\title{
Correction to: Inequality convergence in inefficiency and interprovincial income inequality in Indonesia for 1990-2010
}

\section{Mitsuhiko Kataoka ${ }^{1}$}

\section{Correction to: Asia-Pac J Reg Sci \\ DOI 10.1007/s41685-017-0051-3}

In original publication of the article, the author's first name and family name has been swapped incorrectly. The correct name should read as Mitsuhiko Kataoka.

The original article has been corrected.

The online version of the original article can be found under doi:10.1007/s41685-017-0051-3.

Mitsuhiko Kataoka

mkataoka@rikkyo.ac.jp

1 College of Business, Rikkyo University, 3-34-1 Nishiikebukuro, Toshima-ku, Tokyo 171-8501, Japan 